\title{
BOZDAĞLAR MASIIFI'NDEKİ (KONYA, ORTA ANADOLU) KIVRIMLARIN GEOMETRİK SINIFLAMASI
}

\author{
${ }^{1}$ Melikan AKBAŞ ${ }^{(\mathbb{D})},{ }^{2}$ Yaşar EREN \\ Konya Teknik Üniversitesi, Mühendislik ve Doğa Bilimleri Fakültesi, Jeoloji Mühendisliği Bölümü, Konya, \\ TÜRKIYYE \\ ${ }^{1}$ makbas@ktun.edu.tr, ${ }^{2}$ yeren@ktun.edu.tr
}

(Geliş/Received: 23.12.2020; Kabul/Accepted in Revised Form: 23.02.2021)

ÖZ: Bu çalışmada Bozdağlar Masifi'ndeki (Konya Kuzeyi) deforme kayaçlarda gözlenen kıvrımların geometrik sınıflamaları ve oluşum mekanizması açısından birbirleriyle karşılaştırılması amaçlanmıştır. Altınekin, Meram-Dereköy ve Sarayönü bölgelerindeki Paleozoyik yaşlı metamorfik kayaçlarda gelişen toplamda yüze yakın kıvrım analiz edilerek eğim izogonları ve kanatlar arası açıya göre sınıflandırılmıştır. Dikey kalınlık grafikleri oluşturulan kıvrımlar için yassılma oranları hesaplanmıştır. Çalışma alanlarında yapılan geometrik sınıflamalarla, bölgede yassılmıs paralel kıvrımların egemen olduğu ve kompetent tabakaların sınıf 1C, inkompetent tabakaların sınıf 2 ve sınıf 3 türü kıvrımlar oluşturacak şekilde kıvrımlandıkları görülmüştür. Altınekin bölgesindeki yassılmış sınıf 1C türü kıvrımlara ait yassılma oranları $(\sqrt{\lambda 2} / \lambda 1)$ kompetent (dayanımlı) tabakalar için 0.4-0.8, inkompetent (dayanımsız) tabakalar için 0.3-0.8, Meram-Dereköy bölgesindeki yassılmış sınıf $1 C$ türü kıvrımlara ait yassılma oranı $(\sqrt{\lambda} 2 / \lambda 1)$ kompetent tabakalar için 0.5-0.8, Sarayönü bölgesindeki yassılmış sınıf 1C türü kıvrımlara ait yassılma oranı $(\sqrt{\lambda} 2 / \lambda 1)$ kompetent tabakalar için 0.7-0.9 aralığındadır. Yapılan Fleuty sınıflamasına göre ise yassılma oranlarıyla uyumlu olarak kıvrımların her üç bölgede benzer şekilde açık, dar ve sıkışık kıvrımlar olarak geliştiği, sadece Meram-Dereköy bölgesinde açık kıvrım gelişmediği belirlenmiştir.

Anahtar Kelimeler: Bozdağlar Masifi, Altınekin, Meram-Dereköy, Sarayönü, Kıırım, Eğim İzogonları, Fleuty Sinuflamast.

\section{Geometrical Classification of Folds in the Bozdağlar Massif (Konya, Central Anatolia)}

ABSTRACT: In this study, it is aimed to make geometrically classification and find formation mechanism of mesoscopic folds of that are occur in Bozdağlar Massif (Northern Konya), and to compare them. In the context of the study, nearly a hundred mesoscopic folds which are developed on metamorphic rocks were analyzed in the Altınekin, Meram-Dereköy and Sarayönü regions. The folds are classified based on the dip isogons and interlimb angles. The orthogonal thickness graphs of folds were constructed, and the flattening ratios were calculated. According to the geometrical classification of the folds it is detected that the flattened parallel folds (Class 1C) are the dominant fold type in the deformed rocks of the Bozdağlar Massif, and the folds in the competent rocks are generally represented by the Class $1 \mathrm{C}$, whereas the folds of intervening incompetent rocks are characterized by Class 2 and Class 3 . The Flattening ratios $(\sqrt{\lambda} 2 / \lambda 1)$ of Class 1C folds of Altınekin area are 0.4-0.8 for competent rocks and 0.3-0.8 for incompetent rocks. In the Meram-Dereköy area these ratio $(\sqrt{\lambda} 2 / \lambda 1)$ vary between 0.5 to 0.8 for folds in the competent rocks. The Class $1 \mathrm{C}$ folds that are observed in the vicinity of the Sarayönü area show 0.7 to 0.9 flattening value ( $\sqrt{\lambda 2} / \lambda 1)$. According to the Fleuty classification, it was determined that in accordance with flattening rates, 
folds developed as open, narrow and tight folds in all three regions, except only open folds did not develop in the Meram-Dereköy region.

Key Words: Bozdağlar Massif, Altınekin, Meram-Dereköy, Sarayönü, Folds, Dip isogons, Fleuty classification.

\section{GİRIŞ (INTRODUCTION)}

İnceleme alanları, Bozdağlar Masifi'ne ait deforme kayaçların yüzeylediği Konya İlinin kuzeyindeki Altınekin ve Sarayönü ile çoğunlukla ofiyolitik kayaçların yüzeylediği Meram-Dereköy ilçelerinde yer almaktadır (Şekil 1). Bozdağlar Masifi'nde yürütülen ilk ve temel çalışmalarda, Brennich (1954) Konya çevresinin 1/100.000 ölçekli jeolojik haritasını hazırlayarak bölgenin stratigrafik özelliklerini, Niehoff (1961) bölgede geniş yayılımlı Permo-Mesozoyik yaşlı kayaçların varlığını ve Kaaden (1966) ise bölgedeki kayaçların Hersiniyen orojeni ile ilişkili olarak mavi-şist metamorfizmasına uğradığını ortaya koymuşlardır. Göğer ve Kıral (1969) ilk kez litostratigrafi kurallarına uygun olarak bölgede yüzeyleyen Permiyen-Kuvaterner yaş aralığındaki kayaçları adlandırmışlardır. Bölgede gerçekleştirilmiş olan detaylı stratigrafik ve tektonik çalışmalarda, Özcan ve diğ. (1988) bölgede Paleozoyik-Mesozoyik yaşlı metamorfik kayaçların bulunduğunu ve Geç Paleozoyik yaşlı birimlerin Karbonifer yaşlı bir yay-ardı havzaya bağlı olarak evrimleştiğini, Eren (1993, 1996a, 1996b) ise Permiyen-Erken Kretase yaşlı Gökçeyurt Grubu'nun bölgedeki görünür temeli oluşturduğunu, Çayırbağı Ofiyolitleri ile Altınekin ve Ladik Metamorfitlerinin bu topluluk üzerinde tektonik olarak yer aldığını belirlemiştir. Son yıllarda Konya ve çevresinde yapılan çalışmalarda bölgenin jeotektonik konumu (Eren ve Kurt, 2000; Eren ve diğ., 2004; Robertson ve Ustaömer, 2009; Robertson ve diğ., 2009, 2013; Göncüoğlu 2011) ve bölgedeki magmatik/volkanik kayaçların köken, tip ve mutlak yaşlandırmalarına (Kurt 1994, 1996, 1997; Akal ve

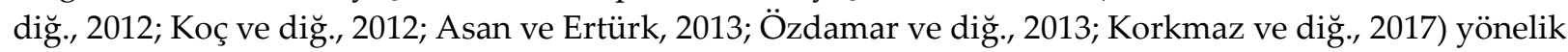
araştırmalar gerçekleştirilmiştir. Eren ve Kurt (2000) ve Eren ve diğ. (2004), Konya kuzeyinde yüzeyleyen kayaçların jeodinamik modellemesini yaparak, Triyas öncesinde güneye dalımlı bir dalma-batma boyunca bölgedeki Paleozoyik yaşı kayaçların deformasyona uğradıklarını ve Mesozoyik öncesi kayaçların Paleo-Tetis ürünü olduklarını belirtmiştir. Robertson ve Ustaömer (2009) ise Konya kuzeyindeki Geç Paleozoyik yaşlı kayaçları Konya Kompleksi olarak adlandırmış ve bunların dalmabatma ve yığışım süreçleri ile geliştiklerini belirtmişlerdir.

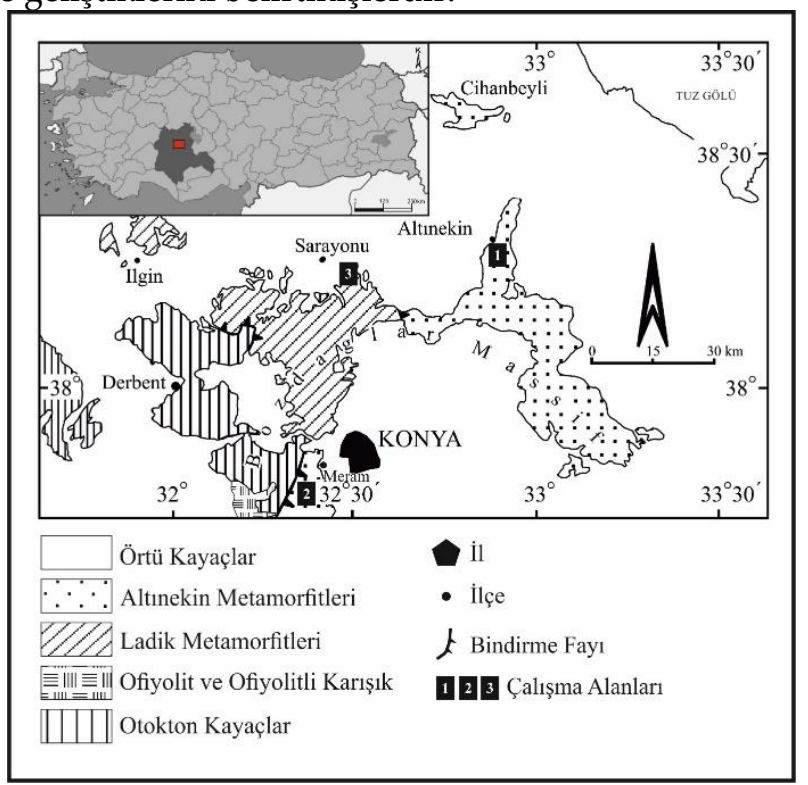

Şekil 1. Bölgenin genelleştirilmiş jeoloji haritası (Eren,1993) ve çalışma alanları. Figure 1. Generalized geology map of the region (Eren, 1993) and location of the study areas. 
Çalışma alanı ve çevrelerindeki kayaçlar düşük-dereceli Paleozoyik-Mesozoyik yaşlı metamorfik kayaçlar (Altınekin, Sarayönü ve Meram-Dereköy) ve Mesozoyik yaşlı Ofiyolit/Ofiyolitli karışık (MeramDereköy) ile temsil olmaktadır (Eren, 1993, 1996a,b; Eren ve Kurt, 2000; Eren ve diğ, 2004). Alpin dağoluşum hareketlerinden etkilenen çalışma sahalarındaki kayaçlardan Ladik Metamorfitleri en az dört evreli deformasyona maruz kalmışken (Eren, 2001), Altınekin Metamorfitleri ise en az altı evreli deformasyona uğrayarak kıvrımlanmış, yapraklanmış ve başkalaşıma uğramıştır (Eren, 2003). Kıvrımlar, deforme olmuş kayaçların en göze çarpan yapılarından biri olup çok farklı özelliklerine göre sınıflandırılmaktadırlar. Bu sınıflamalardan biri de kıvrımlanmış tabakaların kıvrım eksenine dik kesitindeki (profil kesiti) görünümleri kullanılarak, bitişik tabakalarda aynı eğime sahip noktaların birleştirilmesiyle elde edilen eğim izogonlarının (eş eğim çizgileri) birbirlerine göre konumlarından yararlanılarak yapılan sınıflamadır (Ramsay, 1967). Fleuty (1964) tarafından geliştirilen ve kanatlar arası açıya göre yapılan kıvrım sınıflaması, Fleuty'nin yapmış olduğu bir diğer geometrik kıvrım sınıflaması olup, bu çalışmada eğim izogonları sınıflamasına ek olarak çalışılmıştır. Akbaş (2013) tarafından hazırlanan yüksek lisans tezinden üretilen bu çalışmada Bozdağlar Masifi'ndeki deforme kayaçlarda gözlenen kıvrımların eğim izogonları ve kanatlar arası açı yöntemleriyle geometrik ve oluşum mekanizması açısından incelenerek sınıflanması ve üç ayrı bölgede çalışılan kıvrımların oluşum mekanizması açısından birbirleriyle karşılaştırılması amaçlanmıştır.

\section{BÖLGESEL JEOLOJİ (GEOLOGICAL SETTINGS)}

Konya bölgesindeki kayaçlar farklı araştırmacılar tarafından Anatolidler (Ketin, 1966), Torid'ler içindeki Bolkardağı Napı (Özgül, 1976), Afyon-Bolkardağı Zonu (Okay, 1986), Kütahya-Bolkardağı Kuşağ1 (Özcan ve diğ., 1988; Göncüoğlu ve diğ., 2007; Göncüoğlu, 2011) ve Bozdağlar Masifi (Eren, 1993) kapsamında incelenmiştir. Eren (1993) bölgede yer alan kayaçların farklı tektono-stratigrafik özellikler sunduğunu belirtmiş ve Konya kuzeyindeki otokton (?paraotokton) ve allokton nitelikteki kayaçları topluca Bozdağlar Masifi olarak adlandırarak, masifin uyumsuz olarak neo-otokton birimler tarafından örtüldüğünü belirtmiştir. Bölgedeki kayaçlar Göncüoğlu (2011) tarafından ise genel olarak Konya-Tipi Paleozoyik temel, Orta Permiyen örtü, Mesozoyik platform istifleri ve İzmir-Ankara Okyanusu melanj kompleksleri ve ofiyolitleri başlıkları altında incelenmiştir.

İnceleme alanları ve yakın çevrelerindeki kayaçlar genel olarak Bozdağlar Masifi'ne ait kayaçlar (Otokton kayaçlar, Ladik Metamorfitleri, Altınekin Metamorfitleri), okyanusal kayaç toplulukları (Ofiyolit ve Ofiyolitli karışık) ve örtü kayaçlardan oluşmaktadır (Eren, 1993) (Şekil 2). Meram-Dereköy ve çevresini kapsayan alanda, Mesozoyik yaşlı Ofiyolit/Ofiyolitik karışığı kayaçları ve Altınekin Metamorfitlerine ait metamorfik ve meta-sedimanter kayaçlar yüzeylemektedir. Altınekin, Sarayönü ve çevresini kapsayan alanda ise Bozdağlar Masifi'ne ait allokton konumlu farklı litoloji, metamorfizma derecesi ve tektonik özelliğe sahip metamorfik, meta-sedimanter ve meta-magmatik birliklerden oluşan Altınekin ve Ladik Metamorfitleri yer almaktadır (Eren, 1993, 1996a, b; Eren ve Kurt, 2000; Eren ve diğ., 2004). 


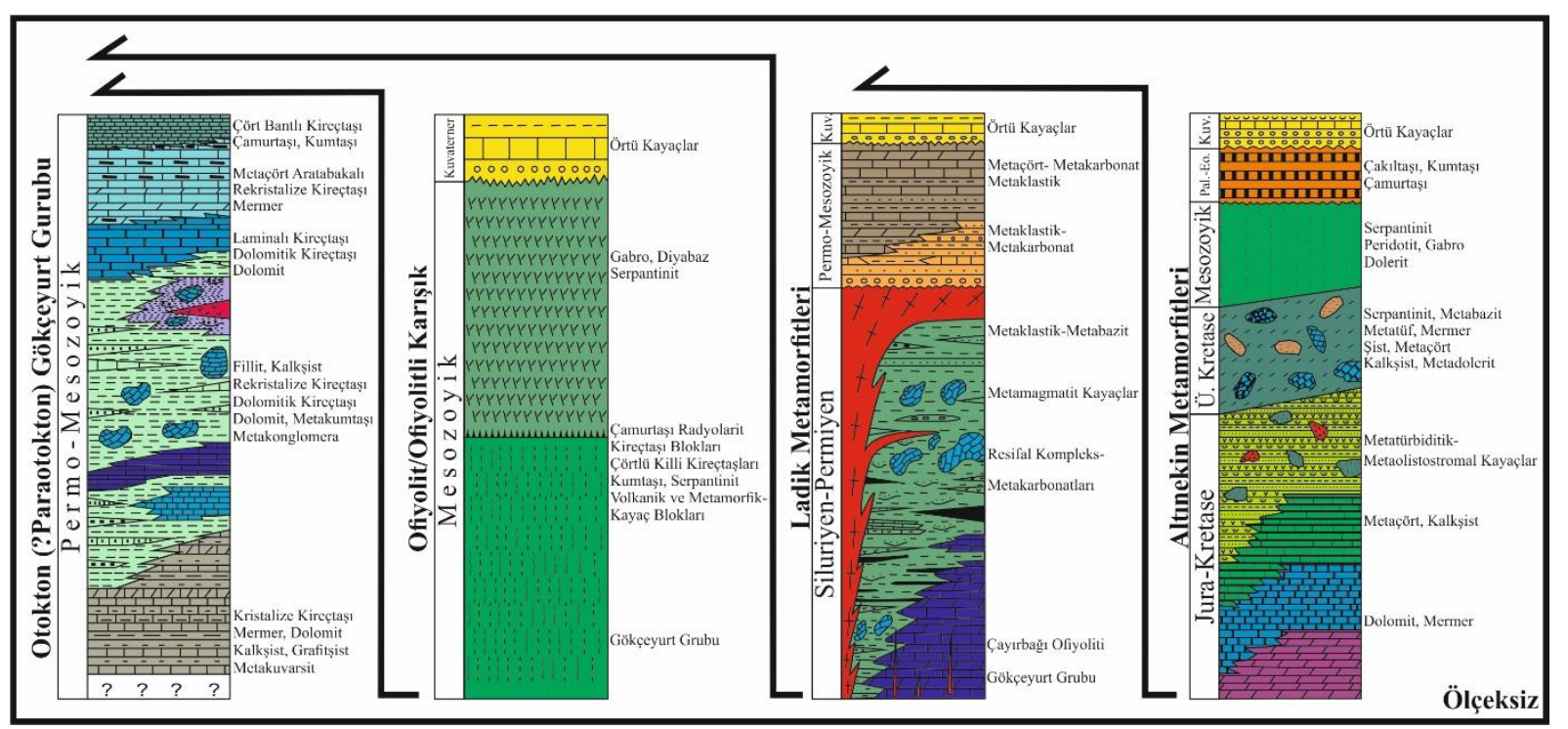

Şekil 2. Çalışma bölgesindeki otokton ve allokton birliklerin genelleştirilmiş dikme kesitleri (Eren, 1993 ve 2003'ten değiştirilerek alınmıştır).

Figure 2. Generalized columnar sections of the autochthonous and allochthonous units in the study area (Modified after Eren, 1993 and 2003).

Otokton (?paraotokton) Gökçeyurt Grubu (Eren, 1993) tabanda gri-siyah, kıt metaçört aratabakalı rekristalize kireçtaşı, mermer, dolomit, kalkşist, grafitşist, fillit, beyaz-pembe metakuvarsit ve monojenik metakuvarsit konglomeraları ile temsil olmaktadır. Bu birimlerin üzerine uyumlu olarak mor ve alacalı fillit, kalkşist, rekristalize kireçtaşı, dolomitik kireçtaşı, dolomit, metakumtaşı ve metakonglomeralı seviyeler gelmektedir. İstifin en üst kısmı ise yanal düşey geçişli olarak, gri-siyah renkli, yer yer laminalı kireçtaşı, dolomitik kireçtaşı ve dolomitler, gri-mavi-beyaz renkli, nadir metaçört aratabakalı rekristalize kireçtaşı, mermerler ve kırmızı-gri renkli çört bantlı pembe-gri renkli kireçtaşı, çamurtaşı ve kumtaşlarıyla karakteristiktir (Göğer ve Kıral, 1969; Özcan ve diğ., 1988; Eren, 1993).

Mesozoyik yaşlı Ofiyolit/Ofiyolitli karışı; tabanda kırmızı çamurtaşı ve radyolaritlerle başlayan çeşitli özellikteki kireçtaşı blokları, çörtlü killi kireçtaşları, çamurtaşı, kumtaşı, serpantinit, volkanik ve metamorfik kayaç bloklarından ve ofiyolitik kayaç kırıntıları içeren bir matriksten oluşmaktadır. Ofiyolit karmaşı üzerine tektonik dokanakla gelen ofiyolit seri ise gri, yeşil ve kahve renkli gabro, diyabaz ve az oranda serpantinitlerle temsil olmaktadır (Eren, 1993).

Eren (1993) tarafından Sızma ve Ardıçı Grupları altında incelenen Ladik Metamorfitlerinin alt kısmına karşılık gelen Sızma Grubu tabanda resifal kompleks metakarbonatlardan ve üstte metaklastikmetabazit ardalanmalarından oluşmaktadır. Meta-magmatit kayaçlar ise bu birimler içerisinde stok ve dayklar halinde gözlenmektedir. Sızma Grubu'nun üzerine uyumsuz olarak gelen Ardıçlı Grubu ise tabandan tavana doğru kaba metaklastik, metaklastik-metakarbonat ardalanması ile metaçört, metakarbonat ve metaklastiklerin ardalanmasından oluşmaktadır. (Özcan ve diğ., 1988; Eren, 1993; Eren

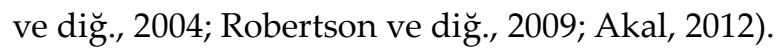

Altınekin Metamorfitleri tabanda yanal düşey geçişli olarak gri-koyu gri-siyah renkli dolomit ve mermerler, beyaz-krem-sarı-gri renkli mermerler, beyaz-gri-pembe metaçört, beyaz-gri mermer, sarı-gri kalkşist ardalanması ile yeşil-mavi renkli metatürbiditik ve metaolistostromal kayaçlarla temsil olmaktadır. Bu birimlerin üzerine tektonik dokanakla serpantinit, yastık lavlar, metabazit, metatüf, metakırıntılı matriksli, mermer, şist, metaçört, kalkşist, metadolerit blokları içeren ofiyotlitli karışık ve bunun da üzerine teknonik dokanakla serpantinit, peridotit, gabro ve dolerit dayklarından oluşan ofiyolitik seri gelmektedir. Altınekin Metamorfitlerinin en üst düzeylerini ise ofiyolitik serinin üzerine uyumsuz olarak gelen kahve-kırmızı ve sarı renkli kırıntılı kayaçlar oluşturmaktadır (Karaman,1986; Özgül ve Göncüoğlu, 1999; Eren, 2003). 
Yöredeki otokton ve allokton özellikli bütün kayaçlar Alpin orojenik olayları ile metamorfizmaya ve çok evreli kıvrımlanmaya uğramışlardır. Bu olaylar büyük bir olasılıkla İç Toros Okyanusu'nun Geç Kretase-Geç Eosen arasındaki kapanmasına bağlı olarak gerçekleşmiştir (Okay 1986; Eren, 1993; Eren ve Kurt 2000, Eren 2001).

\section{MATERYAL VE METOT (MATERIAL AND METHOD)}

Kıvrımlar çok farklı şekillerde sınıflandırılmakta olup bu çalışmada eğim izogonlarına (Ramsay, 1967) ve kanatlar arasındaki açıya (Fleuty, 1964) göre yapılan geometrik kıvrım sınıflamaları kullanılmıştır.

Eğim izogonlarına göre sınıflamada kıvrımlanmış tabakaların kıvrım eksenine dik kesitindeki profil görünümleri kullanılarak, kıvrımlı tabakanın alt ve üst yüzeyindeki aynı eğime sahip noktaların birleştirilmesiyle elde edilen eğim izogonlarının (eş eğim çizgileri) birbirlerine göre konumları yorumlanmaktadır (Ramsay, 1967). Eğim izogonlarına göre yapılan sınıflamada, eksen zonundaki kalınlıklar ( $\mathrm{T}_{0}$ ve $\left.\mathrm{t}_{0}\right)$, kıvrımlanmış tabaka yüzeyleri arasındaki eksen düzlemine paralel kalınlık $\left(\mathrm{T}_{\alpha}\right)$, kıvrımlanmış tabakanın alt ve üst yüzeyi arasındaki dik kalınlık $\left(t_{\alpha}\right)$ ve eğim açısı $(\alpha)$ parametreleri kullanılmaktadır (Şekil 3A). Eğim izogonlarına bağlı olarak Ramsay (1967) tarafından üç temel kıvrım sınıflanmıştır; 1) Yaklaşan eğim izogonlu kıvrımlar (Sınıf 1, 2) Paralel izogonlu kıvrımlar (Sınıf 2 ve 3 ) Uzaklaşan izogonlu kıvrımlar (Sınıf 3) (Şekil 3B).

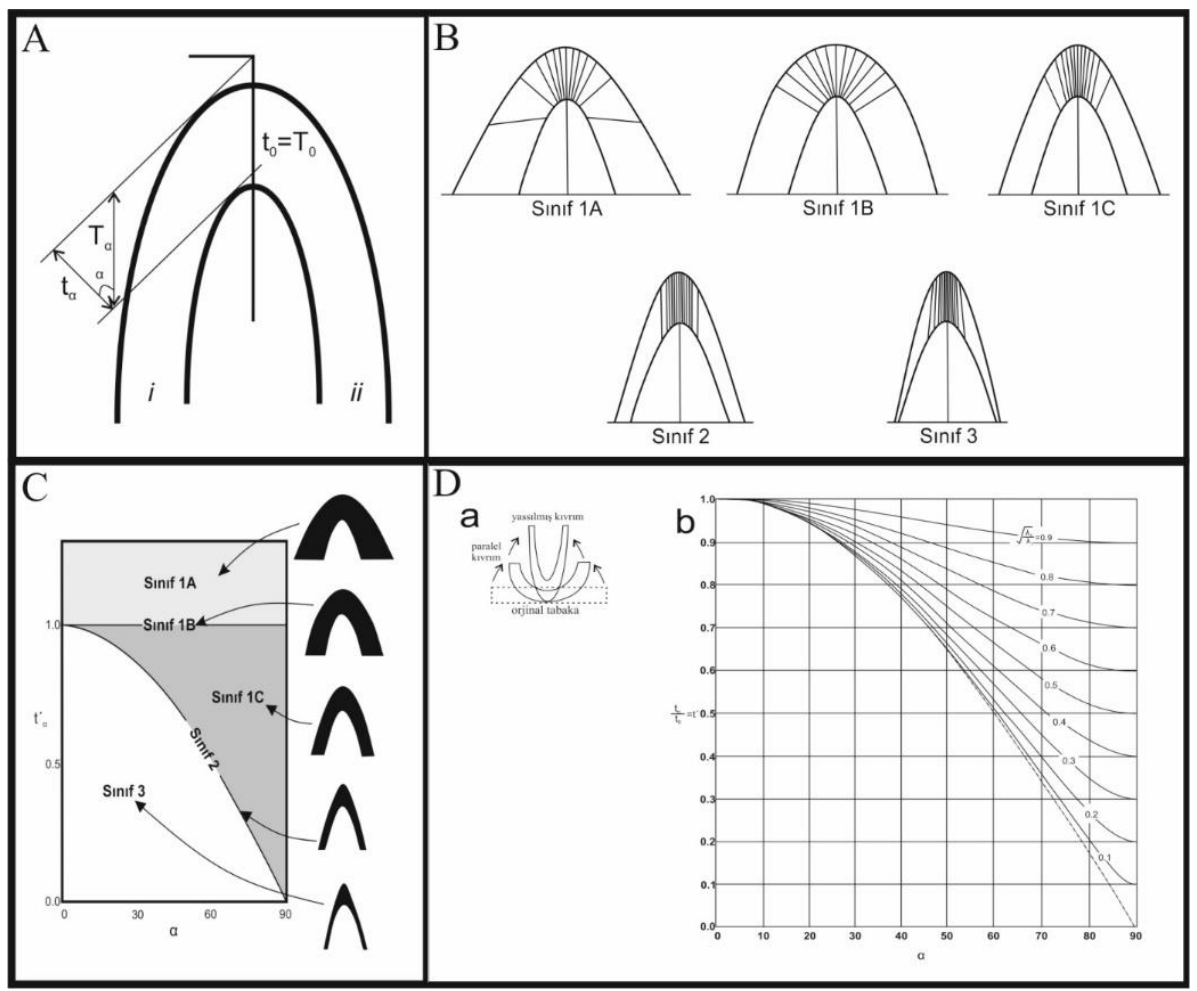

Şekil 3. A) Kıvrım Profili (Ramsay, 1967). To=to: Eksen zonundaki kalınlık, Ta: Kıvrımlanmış tabakanın alt ve üst yüzeyleri arasındaki eksen düzlemine paralel kalınlık, $t_{\alpha}$ : kıvrımlanmış tabakanın yüzeyleri arasındaki dik kalınlık, $\alpha$ : eğim açısı. B) Eğim izogonlarına göre temel kıvrım tipleri (Ramsay, 1967). C) Dikey kalınlık grafiği (Ramsay, 1967). D) Yassılmış paralel kıvrım (Ramsay,1967), a: Paralel kıvrımdan yassılmış kıvrıma geçişi gösterir, b: Sınıf 1C (yassılmış kıvrım) türü kıvrımların yassılma miktarların $(\sqrt{ } \lambda 2 / \lambda 1)$ gösterir abak, $\mathrm{t}^{\prime}{ }_{\alpha}=\mathrm{t}_{\alpha} / \mathrm{t}$ : Eğim açısının değişimine bağlı olarak dikey kalınlığın değişimi bağıntısı, $\alpha$ : Eğim açısı.

Figure 3. A) Fold Profile (Ramsay, 1967). To=to: thickness at the fold hinge, $T_{\alpha}$ : Thickness parallel to axial surface, $t_{\alpha}$ : Orthogonal thickness, $\alpha$ : Angle of dip. B) The main types of folds based on dip isogons (Ramsay, 1967). C) The orthogonal thickness graphs of folds (Ramsay, 1967). D) The flattening fold (Ramsay,1967), a: Projection of the transition from parallel fold to flattened fold, $b$ : Curves of flattening ratios $(\sqrt{ } \lambda 2 / \lambda 1)$ for Class $1 C$ (flattened fold) type folds, $t^{\prime}{ }_{\alpha}=t_{\alpha} / t$ : Orthogonal thickness variation based on angle of dips, $\alpha$ : Angle of dips. 
$\mathrm{T}_{0}, \mathrm{t}_{0}, \mathrm{~T}_{\alpha}, \mathrm{t}_{\alpha}$ ve $\alpha$ parametrelerine bağlı olarak, kıvrım boyunca kıvrımlanan yüzeyin eğim açısının değişimine bağlı olarak dikey kalınlığın değişimi bağıntısı $\mathfrak{t}_{\alpha}^{\prime}=\mathrm{t}_{\alpha} / \mathrm{t}_{0}$ ve eksen yüzeyine paralel kalınlık değişimi bağıntısı $\mathrm{T}^{\prime}{ }_{\alpha}=\mathrm{T}_{\alpha} / \mathrm{T}_{0}$ hesaplanmaktadır (Ramsay, 1967). Elde edilen $\mathrm{t}^{\prime} \alpha$ değeri ile kıvrıma ait eğim açısının değişimine bağlı kanatlardaki dikey kalınlık grafikleri hazırlanabilmekte ve elde edilen grafik üzerinden de kıvrım sınıfları belirlenebilmektedir (Şekil 3C). Yassılmış paralel kıvrımlarda (sınıf 1C) kanatlarda yassılması ve eksen yüzeyi boyunca eşit oranda uzama gerçekleşmektedir (Şekil 3D). Yassılmış paralel kıvrımlardaki deformasyon elipsi uzun ekseni $(\lambda 1)$ ve deformasyon elipsi k1sa ekseni $(\lambda 2)$ verilerine göre yassılma miktarı/deformasyon oranı $(\sqrt{\lambda} 2 / \lambda 1)$ ve/veya $(\sqrt{\lambda} 1 / \lambda 2)$ ise Ramsay (1967) tarafından hazırlanan abak yardımıyla belirlenebilmektedir (Şekil 3D).

Bu çalışmada kullanılan bir diğer kıvrım sınıflama yöntemi de Fleuty (1964) tarafından önerilen kıvrım kanatları arasındaki açıya bağlı olarak yapılan sınıflamadır. Fleuty (1964) sınıflandırmasında kıvrımlar, kıvrımın kanatları arasındaki açıya göre sınıflandırılmaktadır (Şekil 4).

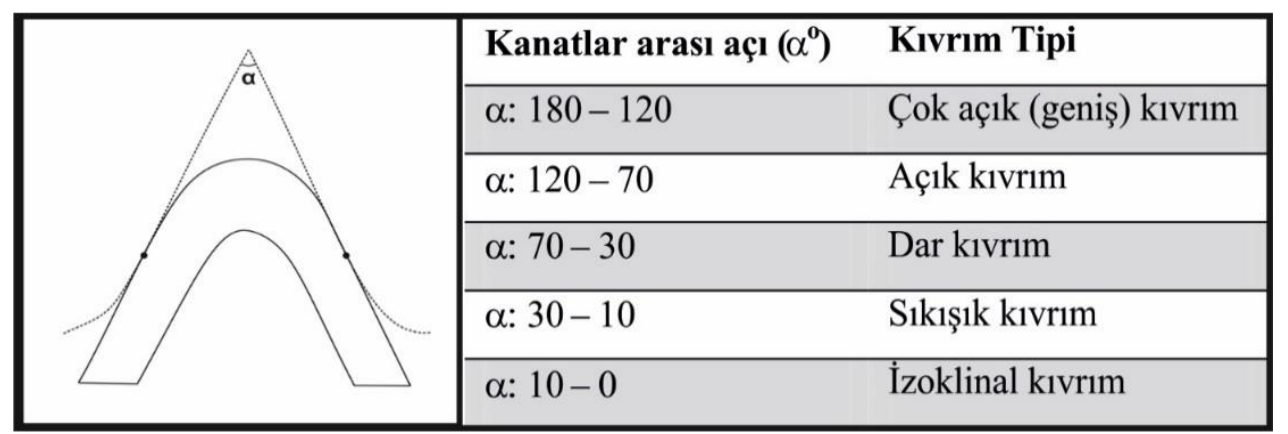

Şekil 4. Kanatlar arasındaki açıya göre kıvrım sınıflandırması (Fleuty, 1964). Figure 4. Classification of the folds based on interlimb angle (Fleuty, 1964).

Bu çalışmadaki Ramsay (1967) ve Fleuty (1964) kıvrım sınıflamaları için kıvrımların arazide çekilen fotoğrafları ve araziden derlenen el örneklerinin kıvrım eksenine dik çekilen fotoğrafları üzerinden kıvrımların şematik resimleri hazırlanmış ve sınıflamalar için gerekli parametreler bu şematik resimler üzerinde çalışılarak elde edilmiştir (Akbaş, 2013). Bu kapsamda Altınekin bölgesinde arazide çekilen 28 farklı fotoğraf üzerinden 36 kıvrımın ve araziden derlenen örneklerden ise 16 kıvrımın şematik resimleri elde edilmiştir (Şekil 5). Meram-Dereköy bölgesindeki Hatip Ofiyolitli Karışığı içindeki çörtlü-kireçtaşı bloklarındaki kıvrımların 16 farklı lokalitede çekilen fotoğrafları üzerinden 18 kıvrımın şematik resimleri elde edilmiştir (Şekil 6). Sarayönü bölgesindeki kıvrımlardan ise aynı şekilde 16 farklı lokalitedeki kıvrımların arazi fotoğraflarından 18 kıvrımın ve araziden derlenen örneklerden ise 5 kıvrımın şematik resimleri elde edilmiştir (Şekil 7).

\section{KIVRIM ANALİİ (ANALYSIS OF FOLD)}

Bu çalışma kapsamında Altınekin, Sarayönü ve Meram-Dereköy bölgelerindeki farklı özellikte deforme olmuş ve kıvrımlanmış birimler geometrik olarak sınıflandırılmıştır. 


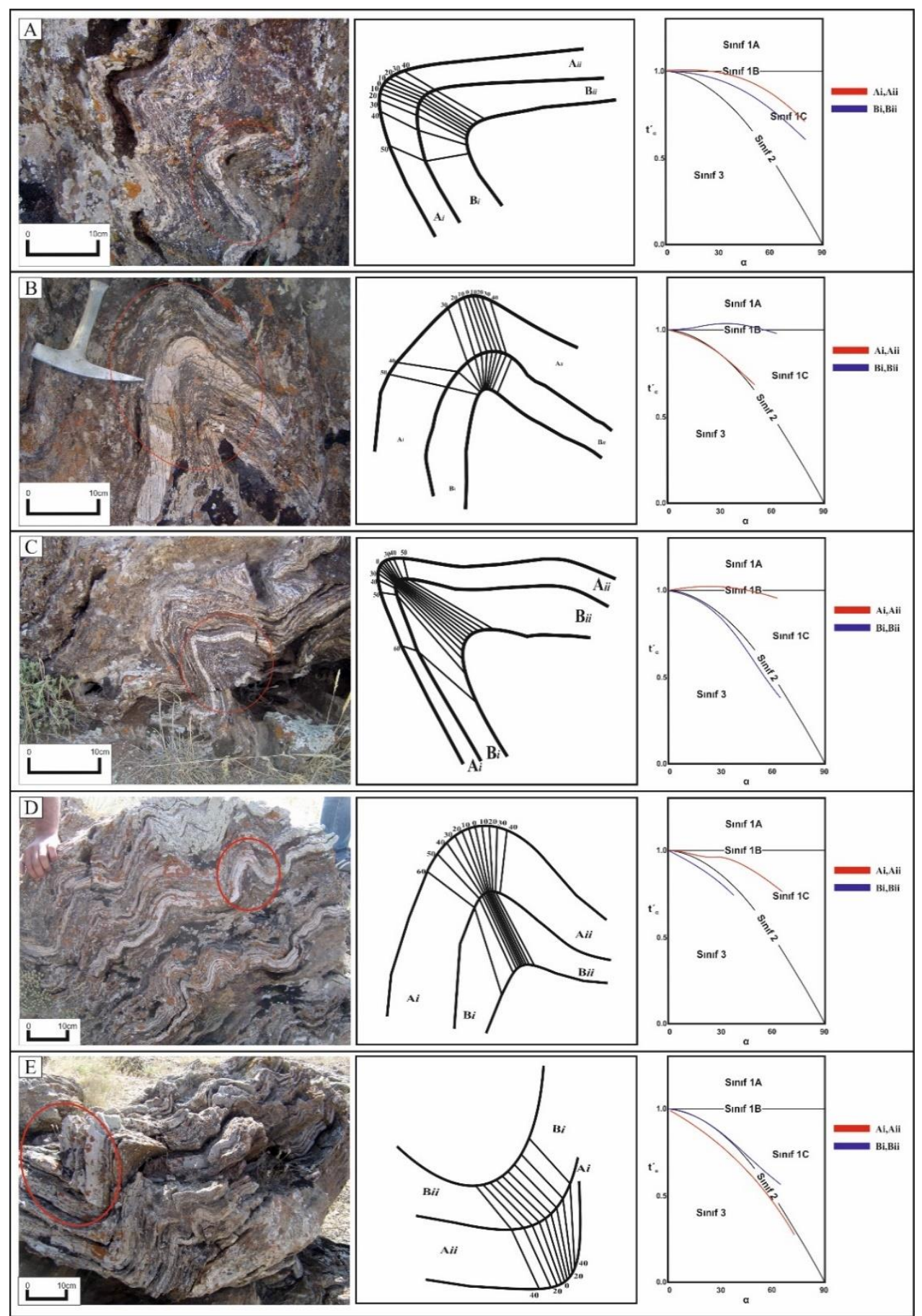

Şekil 5. Altınekin bölgesindeki kıvrımların profilden çekilen fotoğrafları, izogonların çizimi ve dikey kalınlık grafikleri. Ai, Aii, Bi, Bii vd.: Her bir tabakaya verilen ad. A) ALT-1, sinıf1C; B) ALT-2, sinıf 2-sinıf1A; C) ALT-3, sinıf 1A-sinif3; D) ALT-4, sinıf1C-sinif3; E) ALT-5, sinif3-sinif2.

Figure 5. Profile photos of the folds, drawing of isogons and the orthogonal thickness graphs of folds in the Altmekin region. Ai, Aii, Bi, Bii etc.: Name of the each beds of the folds. A) ALT-1, class1C; B) ALT-2, class2-class1A; C) ALT-3, class1A-class3; D) ALT-4, class1C-class3; E) ALT-5, class3-class2. 


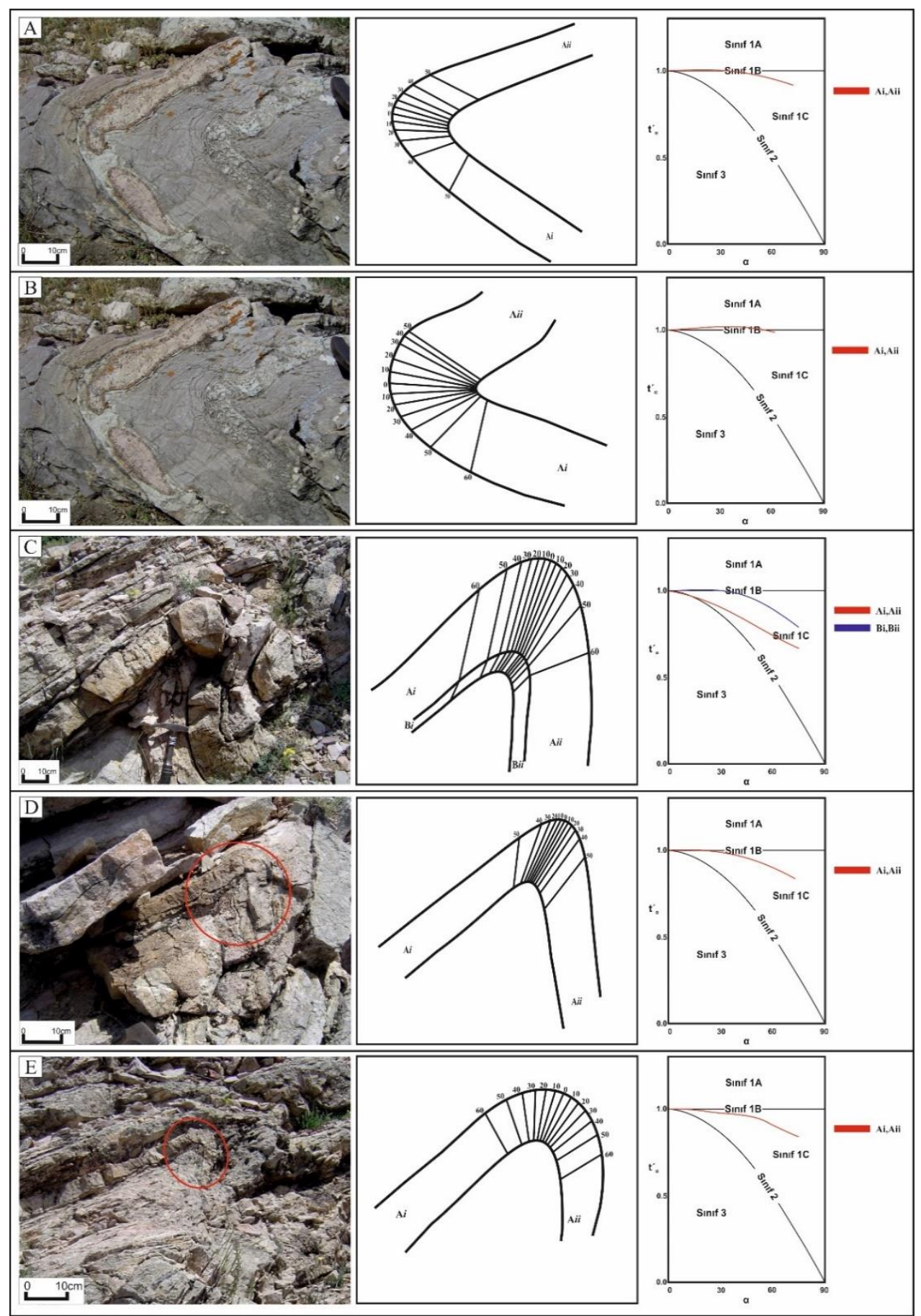

Şekil 6. Meram-Dereköy bölgesindeki kıvrımların profilden çekilen fotoğrafları, izogonların çizimi ve dikey kalınlık grafikleri. Ai, Aii, Bi, Bii vd.: Her bir tabakaya verilen ad. A) MD-1, sinıf1C; B) MD-2, sinıf1A; C) MD-3, sinıf1C; D) MD-4, sinıf 1C; E) MD-5, sinıf1C.

Figure 6. Profile photos of the folds, drawing of isogons and the orthogonal thickness graphs of folds in the Meram-Dereköy region. Ai, Aii, Bi, Bii etc.: Name of the each beds of the folds. A) MD-1, class1C; B) MD-2, class1A; C) MD-3, class1C; D) MD-4, class1C; E) MD-5, class1C. 


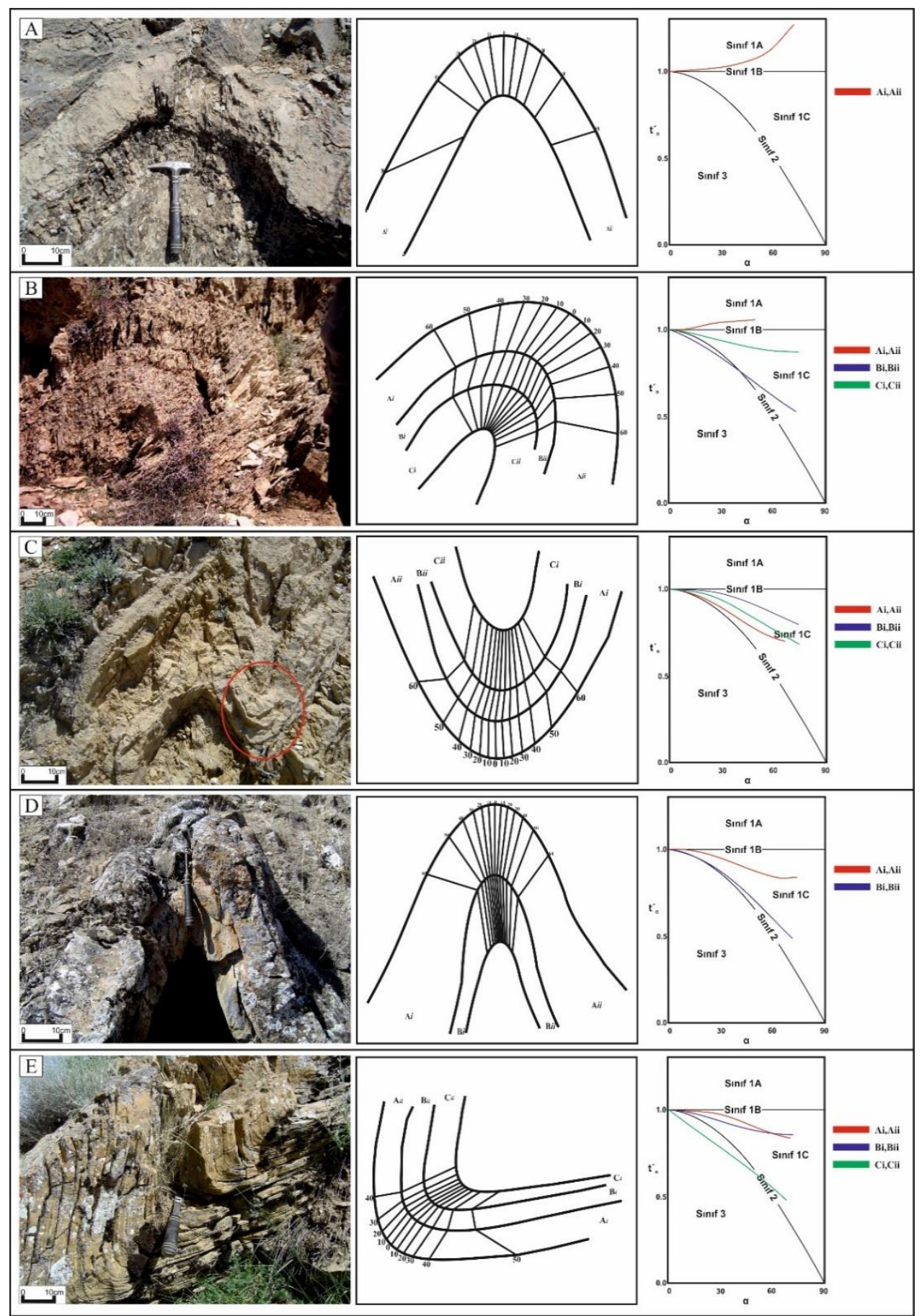

Şekil 7. Sarayönü bölgesindeki kıvrımların profilden çekilen fotoğrafları, izogonların çizimi ve dikey kalınlık grafikleri. Ai, Aii, Bi, Bii vd.: Her bir tabakaya verilen ad. A) SRY-1, snıf 1A; B) SRY-2, sinıf1A-sınıf2-sınıf1C; C) SRY-8, sinıf1C; D) SRY-9, sinıf1C; E) SRY-12, sinıf1C-sınıf3.

Figure 7. Profile photos of the folds, drawing of isogons and the orthogonal thickness graphs of folds in the Sarayönü region. Ai, Aii, Bi, Bii etc.: Name of the each beds of the folds. A) SRY-1, class1A; B) SRY-2, class1A-class2-class1C; C) SRY-8, class1C; D) SRY-9, class1C; E) SRY-12, class1C-class3.

\section{Altınekin Bölgesi (Altınekin Region)}

Altınekin bölgesinde toplamda 52 kıvrım üzerinde yapılan eğim izogonları sınıflamalarına göre, çok evreli kıvrımların kompetent tabakalarının, egemen olarak sınıf 1C, inkompetent tabakalarının ise sınıf 3 veya sınıf 2 türü kıvrımlar olduğu belirlenmiş olup inkompetent tabakaların kompetent tabakalara 
nazaran daha fazla yassıldıkları görülmektedir (Şekil 8A, B). Sınıf 1C olan kompetent tabakalar için $\sqrt{\lambda} 2 / \lambda 1$ değeri 0.4-0.8 arasında, $\sqrt{\lambda} 1 / \lambda 2$ 1.1-2.5 arasında değişmektedir (Şekil $8 C$ ). Buna karşın inkompetent tabakaların yassılma oranının $(\sqrt{\lambda} 2 / \lambda 1)$ 0.3-0.8 aralığında yoğunlaştığı görülmektedir (Şekil 8D). Aynı kıvrım içerisinde sınıf 1C olan kompetent ve inkompetent tabakalarda da inkompetent tabakaların kompetent tabakalara oranla daha fazla yassıldığı görülmektedir. Bölgedeki 1. evre kıvrımlarda ise kompetent tabakaların sınıf 2 veya sınıf 3 türü kıvrım oldukları belirlenmiştir.

Altınekin bölgesindeki Fleuty (1964) kıvrım sınıflamasına göre kıvrımlar dar kıvrım, açık kıvrım ve sıkışık kıvrım olarak sınıflanmıştır (Çizelge 1). Yassılma oranının 0.6-0.9 aralığında olduğu düşük-orta derece yassılmış kıvrımların dar kıvrım veya açık kıvrım olarak geliştiği görülmüştür. Yüksek oranda yassılmış olan 0.4-0.6 aralığında $\sqrt{\lambda 2} / \lambda 1$ değerine sahip kıvrımların ise sıkışık kıvrım olarak geliştiği görülmektedir.

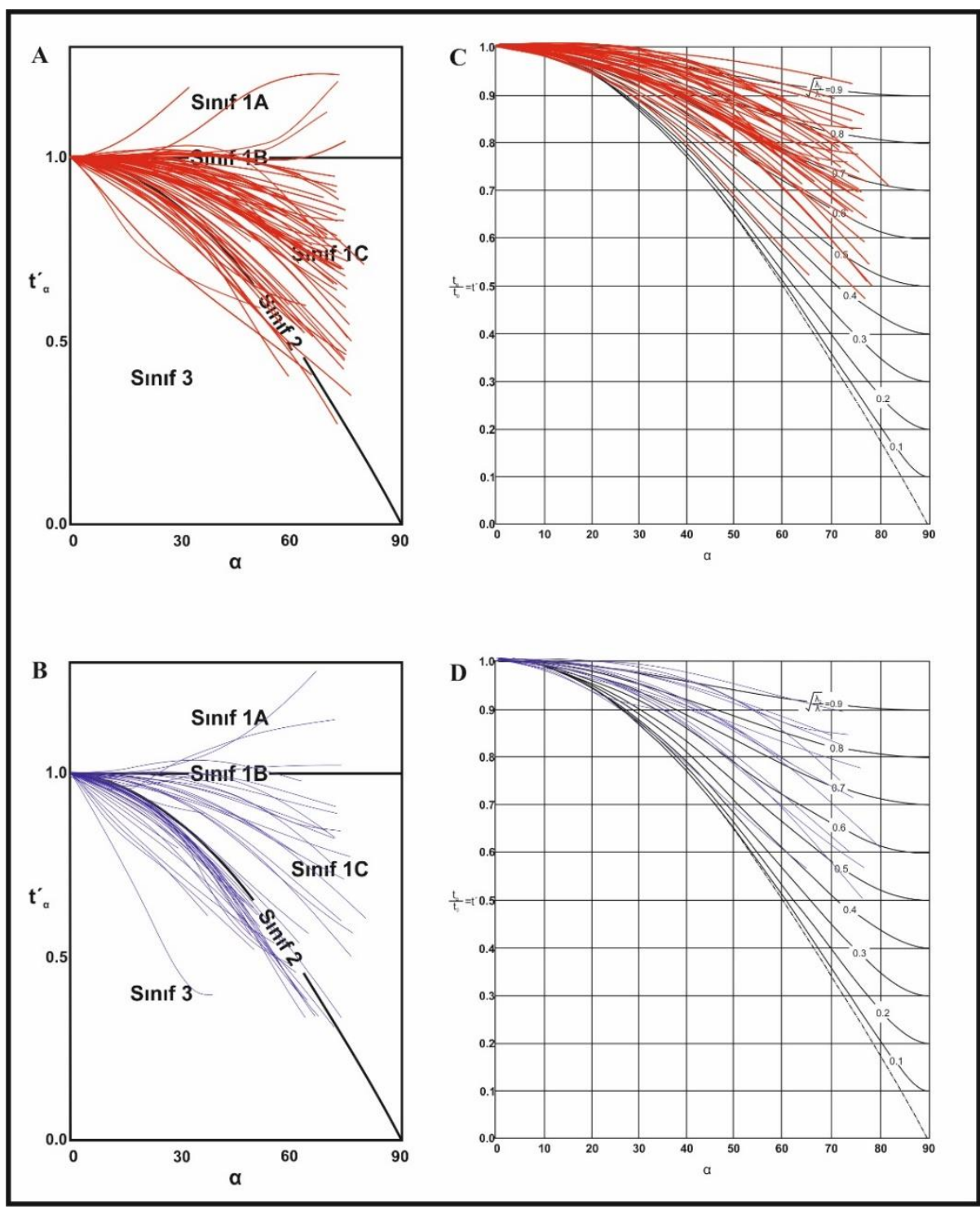

Şekil 8. Altınekin bölgesindeki 52 adet kıvrımın dikey kalınlık ve yassılma oranı grafikleri. A) Kompetent tabakalara ait dikey kalınlık grafiği. B) İnkompetent tabakalara ait dikey kalınlık grafiği. C) Kompetent tabakalara ait yassılma oranı grafiği. D) İnkompetent tabakalara ait yassılma oranı grafiği.

Figure 8. The orthogonal thickness graphs and the flattening ratios graphs of folds in Altmekin region. A) The orthogonal thickness graphs of the competent beds. B) The orthogonal thickness graphs of the incompetent beds. C) The flattening ratios graphs of the competent beds. D) The flattening ratios graphs of the incompetent beds. 
Çizelge 1. Altınekin bölgesinin Fleuty sınıflamasına göre kıvrım türleri.

Table 1. Fold types of Altmekin region based on Fleuty classification.

\begin{tabular}{|c|c|c|c|c|c|c|c|}
\hline $\begin{array}{l}\text { Örnek } \\
\text { No }\end{array}$ & Tabaka & $\alpha^{\circ}$ & Kıvrım Tipi & $\begin{array}{l}\text { Örnek } \\
\text { No }\end{array}$ & Tabaka & $\alpha^{\circ}$ & Kivrım Tipi \\
\hline ALT-1 & A-B & $68-64$ & Dar Kıvrım & ALT-27 & A & 31 & Dar Kıvrım \\
\hline ALT-2 & A-B & $95-86$ & Açık Kıvrım & ALT-28 & A-B-C & $30-58-37$ & $\begin{array}{l}\text { Sıkışık Kıvrım-Dar } \\
\text { Kıvrım }\end{array}$ \\
\hline ALT-3 & A-B & $65-63$ & Dar Kivrım & ALT-29 & A-B-C & 59-64-60 & Dar Kıvrım \\
\hline ALT-4 & A-B & $53-57$ & Dar Kıvrım & ALT-30 & A-B-C & $22-32-61$ & $\begin{array}{l}\text { Sıkışık Kıvrım-Dar } \\
\text { Kıvrım }\end{array}$ \\
\hline ALT-5 & A-B & $73-100$ & Açık Kıvrım & ALT-31 & A & 60 & Dar Kıvrım \\
\hline ALT-6 & A-B-C & $60-59-60$ & Dar Kıvrım & ALT-32 & $\mathrm{A}$ & 79 & Açık Kıvrım \\
\hline ALT-7 & A-B & $67-66$ & Dar Kıvrım & ALT-33 & A-B-C & $31-26-27$ & $\begin{array}{l}\text { Dar Kıvrım-Sıkışık } \\
\text { Kıvrım }\end{array}$ \\
\hline ALT-8 & A-B-C & 89-94-105 & Açık Kıvrım & ALT-34 & A-B-C & $62-69-74$ & $\begin{array}{l}\text { Dar Kıvrım-Açık } \\
\text { Kıvrım }\end{array}$ \\
\hline ALT-9 & A-B & $50-46$ & Dar Kıvrım & ALT-35 & A-B-C & $59-49-67$ & Dar Kıvrım \\
\hline ALT-10 & A-B & $50-69$ & Dar Kıvrım & ALT-36 & $\mathrm{A}$ & 34 & Dar Kıvrım \\
\hline ALT-11 & A-B & $54-77$ & $\begin{array}{l}\text { Dar Kıvrım-Açık } \\
\text { Kıvrım }\end{array}$ & ALT-37 & A-B & $50-44$ & Dar Kıvrım \\
\hline ALT-12 & A-B-C & $79-92-86$ & Açık Kıvrım & ALT-38 & A-B & $108-103$ & Açık Kıvrım \\
\hline ALT-13 & A-B & $47-50$ & Dar Kıvrım & ALT-39 & A-B & $47-48$ & Dar Kıvrım \\
\hline ALT-14 & A-B & $44-49$ & Dar Kıvrım & ALT-40 & A-B & $48-51$ & Dar Kıvrım \\
\hline ALT-15 & A-B & $67-60$ & Dar Kıvrım & ALT-41 & A-B & 70-95 & $\begin{array}{l}\text { Dar Kıvrım-Açık } \\
\text { Kıvrım }\end{array}$ \\
\hline ALT-16 & A-B-C & 94-123-72 & Açık Kıvrım & ALT-42 & A-B-C & $50-45-45$ & Dar Kıvrım \\
\hline ALT-17 & A-B-C & $70-91-98$ & $\begin{array}{l}\text { Dar Kıvrım-Açık } \\
\text { Kıvrım }\end{array}$ & ALT-43 & A & 70 & Dar Kıvrım \\
\hline ALT-18 & A-B-C-D-E & $85-65-77-55-57$ & $\begin{array}{l}\text { Açık Kıvrım-Dar } \\
\text { Kıvrım }\end{array}$ & ALT-44 & A-B & $60-44$ & Dar Kıvrım \\
\hline ALT-19 & A-B & $90-65$ & $\begin{array}{l}\text { Açık Kıvrım-Dar } \\
\text { Kıvrım }\end{array}$ & ALT-45 & A & 70 & Dar Kıvrım \\
\hline ALT-20 & A-B-C-D & 74-70-87-80 & $\begin{array}{l}\text { Açık Kıvrım-Dar } \\
\text { Kıvrım }\end{array}$ & ALT-46 & A-B-C & $70-70-73$ & $\begin{array}{l}\text { Dar Kıvrım-Açık } \\
\text { Kıvrım }\end{array}$ \\
\hline ALT-21 & A-B-C-D & 71-78-74-68 & $\begin{array}{l}\text { Açık Kıvrım-Dar } \\
\text { Kıvrım }\end{array}$ & ALT-47 & A & 60 & Dar Kıvrım \\
\hline ALT-22 & A-B-C-D & 100-85-71-68 & $\begin{array}{l}\text { Açık Kıvrım-Dar } \\
\text { Kıvrım }\end{array}$ & ALT-48 & A-B & $98-97$ & Açık Kıvrım \\
\hline ALT-23 & $\begin{array}{c}\text { A-B-C-D-E-F- } \\
\text { G-H } \\
\end{array}$ & $\begin{array}{c}\text { 97-93-100-91- } \\
\text { 97-94 } \\
\end{array}$ & Açık Kıvrım & ALT-49 & A & 46 & Dar Kıvrım \\
\hline ALT-24 & A-B & $99-110$ & Açık Kıvrım & ALT-50 & A-B & $70-83$ & $\begin{array}{l}\text { Dar Kıvrım-Açık } \\
\text { Kıvrım }\end{array}$ \\
\hline ALT-25 & A-B-C-D & $44-40-52-58$ & Dar Kıvrım & ALT-51 & A-B & $46-55$ & Dar Kıvrım \\
\hline ALT-26 & A-B-C-D-E & 83 & $\begin{array}{l}\text { Açık Kıvrım-Dar } \\
\text { Kıvrım }\end{array}$ & ALT-52 & A & 56 & Dar Kıvrım \\
\hline
\end{tabular}

\section{Meram-Dereköy Bölgesi (Meram-Dereköy Region)}

Meram-Dereköy bölgesinde yer alan 18 adet kıvrımın şematik resimleri üzerinde yapılan izogonal sınıflamalarda kompetent tabakaların egemen olarak sınıf 1C türü kıvrım olarak geliştikleri görülmektedir (Şekil 9A). Az sayıda analiz edilebilen inkompetent tabakaların ise egemen olarak sınıf 3 türü kıvrım olarak geliştikleri belirlenmiştir (Şekil 9B). Sınıf 1C türü olan kıvrımların orta düşük derecede bir yassılma gösterdikleri ve ortalama $0.5-0.8$ aralığında $\sqrt{\lambda} 2 / \lambda 1$ ve 1.1-2.0 aralığında $\sqrt{\lambda} 1 / \lambda 2$ değerine sahip oldukları görülmektedir (Şekil 9C).

Meram-Dereköy bölgesindeki kıvrımlar için yapılan Fleuty (1964) kıvrım sınıflamasına göre kıvrımlar dar kıvrım, açık kıvrım ve sıkışık kıvrım olarak tanımlanmıştır (Çizelge 2). Yassılma oranının 0.7-0.9 
aralığında olduğu ve düşük-orta derece yassılmış kıvrımların dar kıvrım olarak geliştiği, yüksek oranda yassılmış kıvrımların ise sıkışık kıvrım olarak geliştiği belirlenmiştir.

\section{Sarayönü Bölgesi (Sarayönü Region)}

Sarayönü çalışma alanında arazide yerinde (18 adet) ve derlenen örneklerde (5 adet) belirlenen kıvrımlar için yapılan izogonal sınıflamalarda kompetent tabakaların egemen olarak sınıf 1C türü kıvrım olarak geliştikleri, inkompetent tabakaların ise daha fazla deforme olarak sinıf 3 veya sınıf 2 türü kıvrımlar olarak geliştikleri görülmektedir (Şekil 10A, B). Sınıf 1C türü olan kıvrımların dar bir aralıkta bir yassılma gösterdikleri ve ortalama 0.7-0.9 aralığında $\sqrt{\lambda} 2 / \lambda 1$ değerine ve 1.1-1.0 aralığında $\sqrt{\lambda} 1 / \lambda 2$ değerine sahip oldukları belirlenmiştir (Şekil 10C, D).

Sarayönü bölgesindeki yapılan Fleuty (1964) kıvrım sınıflamasına göre kıvrımlar dar kıvrım ve açık kıvrım olarak sınıflanmıştır (Çizelge 3). Yassılma oranının 0.7-0.9 aralığında olduğu düşük-orta derece yassılmış kıvrımların dar kıvrım olarak geliştiği, daha az oranda yassılmış kıvrımların ise açık kıvrım olarak geliştiği belirlenmiştir.

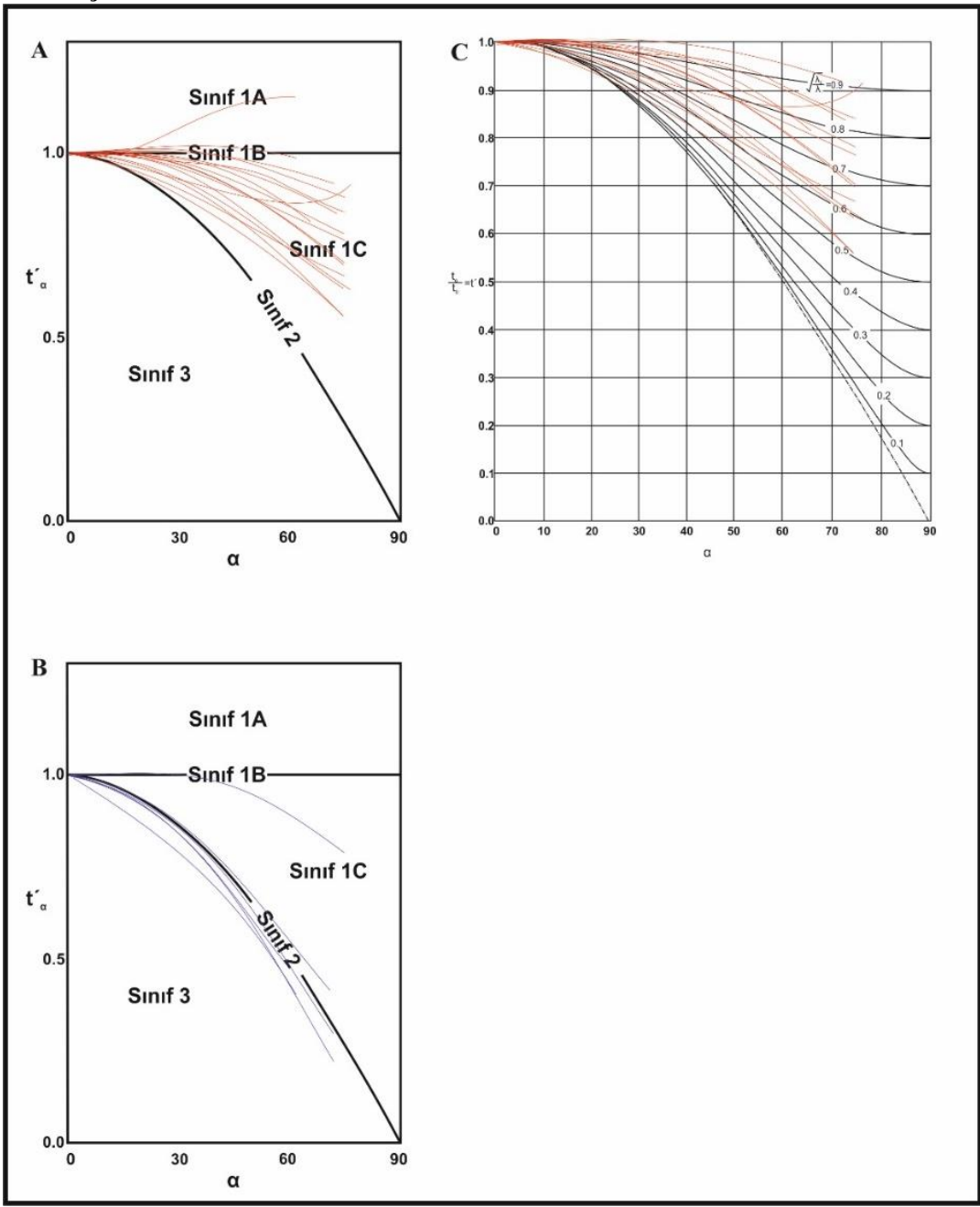

Şekil 9. Meram-Dereköy bölgesindeki 18 adet kıvrımın dikey kalınlık ve yassılma oranı grafikleri. A) Kompetent tabakalara ait dikey kalınlık grafiği. B) İnkompetent tabakalara ait dikey kalınlık grafiği.

C) Kompetent tabakalara ait yassılma oranı grafiği.

Figure 9. The orthogonal thickness graphs and the flattening ratios graphs of folds in Meram-Dereköy region. A) The orthogonal thickness graphs of the competent beds. B) The orthogonal thickness graphs of the incompetent beds. C) The flattening ratios graphs of the competent beds. 
Çizelge 2. Meram-Dereköy bölgesinin Fleuty sınıflamasına göre kıvrım türleri.

Table 2. Fold types of Meram-Dereköy region based on Fleuty classification.

\begin{tabular}{cccc} 
Örnek No & Tabaka & $\boldsymbol{\alpha}^{\circ}$ & Kıvrım Tipi \\
\hline MD-1 & A & 70 & Dar Kıvrım \\
\hline MD-2 & A & 44 & Dar Kıvrım \\
\hline MD-3 & A-B & $49-46$ & Dar Kıvrım \\
\hline MD-4 & A & 68 & Dar Kıvrım \\
\hline MD-5 & A & 43 & Dar Kıvrım \\
\hline MD-6 & A & 37 & Dar Kıvrım \\
\hline MD-7 & A & 44 & Dar Kıvrım \\
\hline MD-8 & A-B & $41-37$ & Dar Kıvrım \\
\hline MD-9 & A & 37 & Dar Kıvrım \\
\hline
\end{tabular}

\begin{tabular}{cccc} 
Örnek No & Tabaka & $\boldsymbol{\alpha}^{\circ}$ & Kıvrım Tipi \\
\hline MD-10 & A & 26 & Sıkışık Kıvrım \\
\hline MD-11 & A & 60 & Dar Kıvrım \\
\hline MD12 & A-B & $20-18$ & Sıkışık Kıvrım \\
\hline MD-13 & A & 36 & Dar Kıvrım \\
\hline MD-14 & A & 61 & Dar Kıvrım \\
\hline MD-15 & A & 37 & Dar Kıvrım \\
\hline MD-16 & A-B & $59-59$ & Dar Kıvrım \\
\hline MD-17 & A-B & $29-41$ & Sıkışık Kıvrım \\
\hline MD-18 & A-B & $23-26$ & Sıkışık Kıvrım \\
\hline
\end{tabular}

Çizelge 3. Sarayönü bölgesinin Fleuty sınıflamasına göre kıvrım türleri. Table 3. Fold types of Sarayönü region based on Fleuty classification.

\begin{tabular}{cccc}
\hline Örnek No & Tabaka & $\boldsymbol{\alpha}^{\circ}$ & Kıvrım Tipi \\
\hline SRY-1 & A & 85 & Açı Kıvrım \\
\hline SRY-2 & A-B-C & $72-76-80$ & Açı Kıvrım \\
\hline SRY-3 & A-B & $41-48$ & Dar Kıvrım \\
\hline SRY-4 & A & 110 & Açı Kıvrım \\
\hline SRY-5 & A-B & $96-97$ & Açı Kıvım \\
\hline SRY-6 & A & 105 & Açlk Kıvrım \\
\hline SRY-7 & A & 57 & Dar Kıvrım \\
\hline SRY-8 & A-B-C & $60-60-65$ & Dar Kıvrım \\
\hline SRY-9 & A-B & $60-37$ & Dar Kıvrım \\
\hline SRY-10 & A-B-C-D & $77-88-81-78$ & Açı Kıvım \\
\hline SRY-11 & A-B & $78-74$ & Açlk Kıvrım \\
\hline SRY-12 & A-B-C & $85-81-80$ & Açı Kıvrım \\
\hline & & &
\end{tabular}

\begin{tabular}{cccc}
\hline Örnek No & Tabaka & $\boldsymbol{\alpha}^{\circ}$ & Kıvrım Tipi \\
\hline SRY-13 & A & 29 & Sıkışık Kıvrım \\
\hline SRY-14 & A & 59 & Dar Kıvrım \\
\hline SRY-15 & A-B-C & $32-35-31$ & Dar Kıvrım \\
\hline SRY-16 & A-B & $21-17$ & Sıkışık Kıvrım \\
\hline SRY-17 & A-B-C & $62-64-69$ & Dar Kıvrım \\
\hline SRY-18 & A & 70 & Dar Kıvrım \\
\hline SRY-19 & A-B-C-D & $93-89-90-78$ & Açık Kıvrım \\
\hline SRY-20 & A-B & $105-92$ & Açık Kıvrım \\
\hline SRY-21 & A & 62 & Dar Kıvrım \\
\hline SRY-22 & A-B & $87-97$ & Açık Kıvrım \\
\hline SRY-23 & A-B & $65-62$ & Dar Kıvırı \\
\hline
\end{tabular}




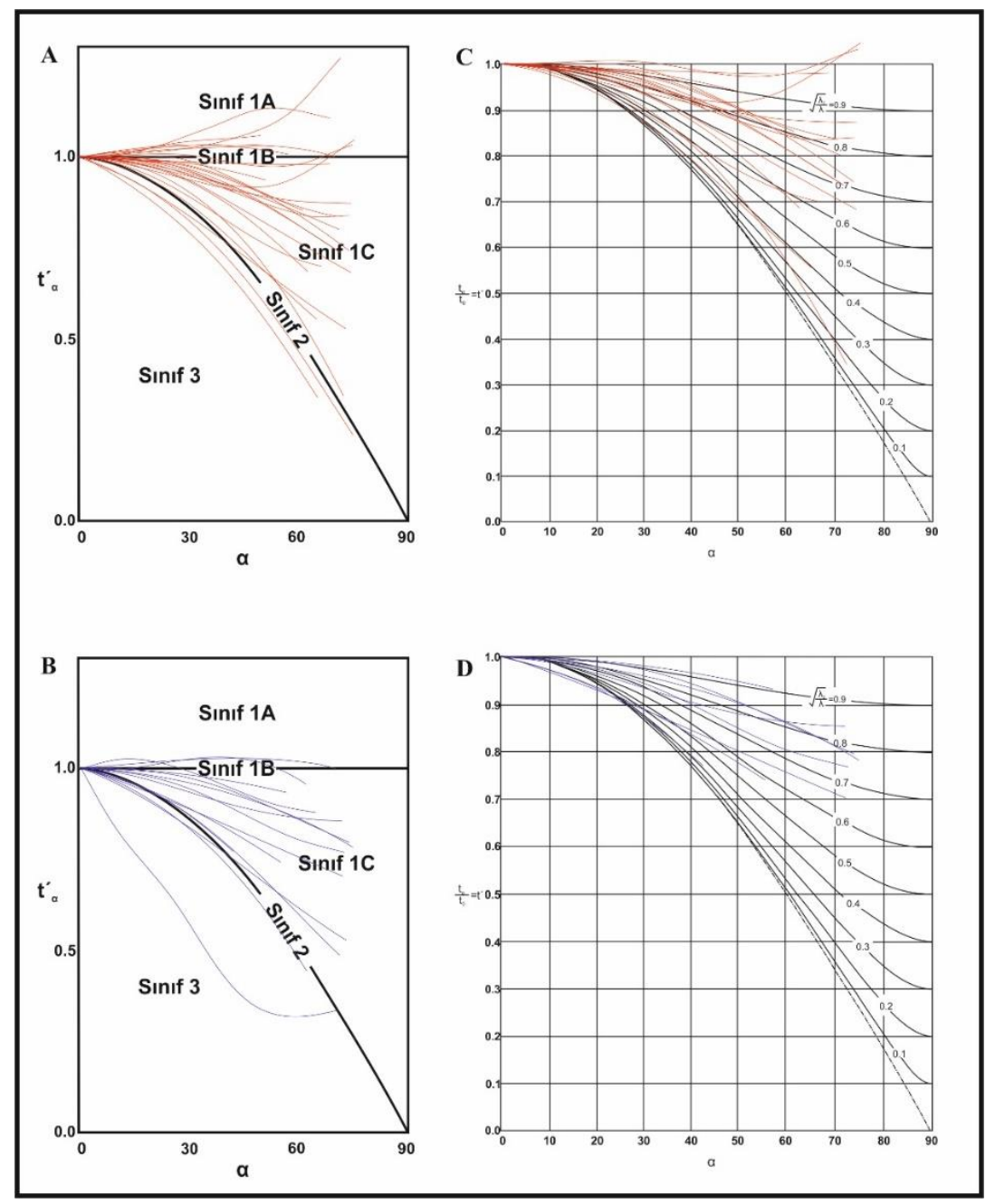

Şekil 10. Sarayönü bölgesindeki 23 adet kıvrımın dikey kalınlık ve yassılma oranı grafikleri. A) Kompetent tabakalara ait dikey kalınlık grafiği. B) İnkompetent tabakalara ait dikey kalınlık grafiği. C) Kompetent tabakalara ait yassılma oranı grafiği. D) İnkompetent tabakalara ait yassılma oranı grafiği.

Figure 10. The orthogonal thickness graphs and the flattening ratios graphs of folds in Sarayönü region. A) The orthogonal thickness graphs of the competent beds. B) The orthogonal thickness graphs of the incompetent beds. C) The flattening ratios graphs of the competent beds. D) The flattening ratios graphs of the incompetent beds.

\section{SONUÇLAR (RESULTS)}

Altınekin, Meram-Dereköy ve Sarayönü bölgelerindeki mesoskopik kıvrımlar için geometrik sınıflamalar yapılmıştır. Yapılan geometrik kıvrım sınıflamaları ve bölgenin tektonik evrimi dikkate alındığında aşağıdaki sonuçlar elde edilmiştir;

1) Çalışma alanlarında yapılan geometrik sınıflamalarla, bölgede yassılmış paralel kıvrımların egemen olduğu ve kompetent tabakaların sınıf 1C, inkompetent tabakaların sınıf 2 ve sınıf 3 türü kıvrımlar oluşturacak şekilde kıvrımlandıkları görülmüştür.

2) Yapılan Fleuty sınıflamasına göre ise yassılma oranlarıyla uyumlu olarak kıvrımların, Altınekin bölgesinde açık, dar ve sıkışık kıvrım, Meram-Dereköy bölgesinde dar, sıkışık kıvrım, Sarayönü bölgesinde ise açık kıvrım, dar kıvrım ve sıkışık kıvrım şeklinde geliştikleri belirlenmiştir.

3) Altınekin bölgesinde gelişen en az 6 evreli deformasyon sonucu gelişen kıvrımların, oluşum mekanizmasına bakıldığında, bölgede YB/DS (Yüksek basınç/düşük sıcaklık) ve daha sonra düşük sıcaklık metamorfizmasıyla bükülme, fleksürel akma, fleksürel kayma mekanizmalarına uygun bir kıvrımlanmanın geliştiği ve ilerleyen deformasyonla birlikte yassılmış kıvrımların geliştiği görülmüştür. 
4) Meram-Dereköy bölgesinde gelişen kıvrımlara ait izogonal kıvrım türleri bölgedeki kıvrımların esas olarak bükülme mekanizmasına uygun olarak geliştiğini göstermektedir. Bükülme mekanizması ile oluşan paralel kıvrımların ilerleyen deformasyon ile paralel yassılmış kıvrımlara dönüştügü görülmüştür.

5) Sarayönü bölgesinde gelişen izogonal kıvrımların ilerleyen deformasyonlarla birlikte fleksürel akma ve kayma mekanizmalarına uygun geliştiği belirlenmiştir. Deformasyon süreçlerinde yassılma devam etmiş ve yassılmış kıvrımlar da gelişmişlerdir.

6) Alanlara göre gelişen kıvrım sınıflarına, kıvrım geometrilerine ve aynı kompetentliğe sahip Sınıf 1C kıvrımlarının yassılma oranlarına bakıldığında, Altınekin Metamorfitlerinin, Meram-Dereköy alanındaki kayaçlara, Meram Dereköy alanındaki kayaçların da Sarayönü alnındakilere göre daha fazla deforme oldukları görülmektedir.

\section{SEMBOLLER (SYMBOLS)}

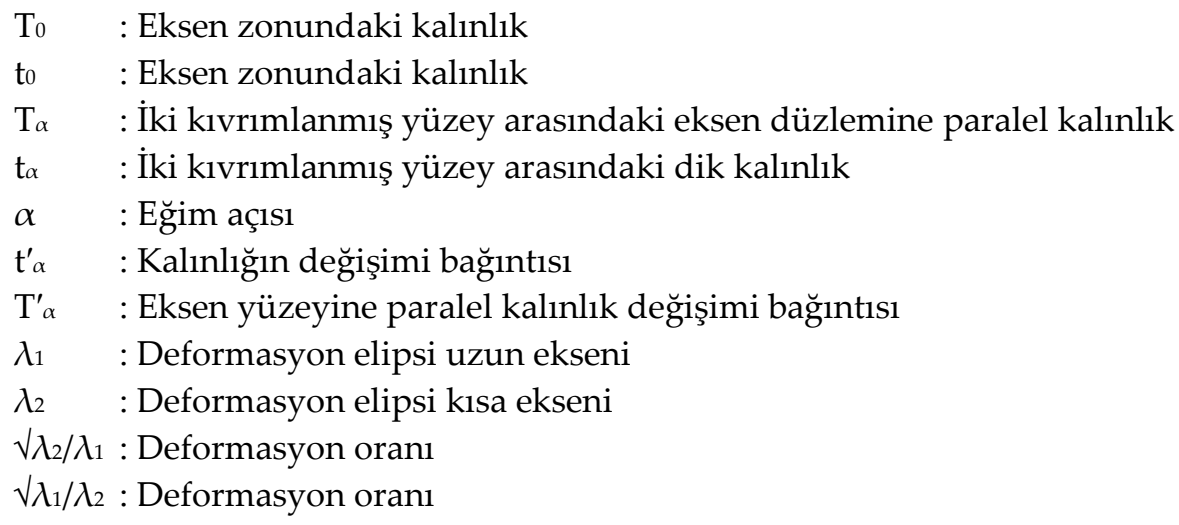

\section{KAYNAKLAR (REFERENCES)}

Akbaş, M., 2013, Bozdağlar Masifi'ndeki (Konya Kuzeyi) Kıvrımların Geometrik ve Oluşum Mekanizması Açısından Sınıflaması, Yüksek Lisans Tezi, Selçuk Üniversitesi, Fen Bilimleri Enstitüsü, Konya.

Akal, C., Candan, O., Koralay, O.E., Oberhänsli, R., Chen, F., Prelević, D., 2012, “Early Triassic potassic volcanism in the Afyon Zone of the Anatolides/Turkey: implications for the rifting of the NeoTethys", International Journal of Earth Sciences, Vol. 101, No. 1, pp. 177-194.

Asan, K., Ertürk, M.A., 2013, “First Evidence of Lamprophyric Magmatism from the Konya Region, Turkey: a Genetic Link to High-K Volcanism", Acta Geologica Sinica (English Edition), Vol. 87, No. 6, pp. 1617-1629.

Brennich, G., 1954, “1/100 000 ölçekli genel jeolojik harita izahnamesi. Akşehir (90-1, 2, 3, 4) ve Ilgin (91/1 ve 91/3) paftaları", Maden Tetkik ve Arama Enstitüsü, Derleme Rapor, Rapor No. 2515.

Eren, Y., 1993, "Konya kuzeybatısında Bozdağlar Masifinin otokton ve örtü birimlerinin stratigrafisi", Türkiye Jeoloji Bülteni, Cilt. 36, ss. 7-23.

Eren, Y., "Ilgın-Sarayönü (Konya) güneyinde Bozdağlar Masifi'nin Stratigrafisi ve Jeoloji Evrimi”, K.T.Ü. Jeoloji Mühendisliği Bölümü 30. Yıl Sempozyumu Bildirileri, KTÜ, Trabzon, Cilt 1, 694-707, 1996 a.

Eren, Y., 1996b, “Ilgın-Sarayönü (Konya) Güneyinde Bozdağlar Masifi'nin Yapısal Özellikleri”, Türkiye Jeoloji Bülteni, Cilt 39, Sayı 2, ss. 49-64.

Eren, Y., 2001; “The Polyphase Alpine Deformation at the Northern Edge of the Menderes-Taurus Block, North Konya, Central Turkey", Journal of Asian Earth Sciences, Vol. 19, No. 6, pp. 737-749.

Eren Y., 2003, "Tuzgölü Havzası Güneybatısındaki (Altınekin-Konya) Temel Kayaçlarının Jeolojisi", Türkiye Petrol Jeologları Derneği (Haymana-Tuzgölü-Ulukışla Basenleri Uygulamalı Çalışma-Özel sayl), Cilt 5, ss. 113-127.

Eren, Y., Kurt, H., 2000, “The Stratigraphical, Geochemical and Geodynamical Modelling of the Northeast Margin of Menderes-Taurus Block", S.Ü. Mühendislik Fakültesi Dergisi, Vol. 15, No. 1, pp. 26-41. 
Eren,Y., Kurt, H., Rosselet, F., G.M. Stampfli, 2004, "Palaeozoic Deformation and Magmatism in the Northern Area of the Anatolide Block (Konya), Witness of the Palaeotethys Active Margin, Eclogae Geologicae Helvetiae, Vol. 97, No. 2, pp. 293-306.

Fleuty, M.J., 1964, “The Description of Folds”. Geological Association Proceeding, Vol. 75, pp. 461-492.

Göğer, E., Kıral, K., 1969, “Kızılören dolayının jeolojisi”, Maden Tetkik ve Arama Enstitüsü, Rapor No. 5204.

Göncüoğlu, M. C., 2011, “Kütahya-Bolkardağ Kuşağının Jeolojisi”, Maden Tetkik ve Arama Dergisi, Cilt 142, ss. 227-282.

Göncüoğlu, M. C., Çapkınoğlu, Ş., Gürsu, S., Noble, P., Turhan, N., Tekin U. K., Okuyucu, C., Göncüoğlu, Y., 2007, "The Mississippian in the Central and Eastern Taurides (Turkey): constraints on the tectonic setting of the Tauride-Anatolide Platform", Geologica Carpathica, Vol. 58, No. 5, pp. 427442.

Kaaden, G., 1966, "The significance and distribution of glaucophane rocks in Turkey", Bulletin Mineral Research Exploration Institute of Turkey, Vol. 67, pp. 37-67.

Karaman, M.E., 1986, “Altınekin (Konya) çevresinin jeolojisi ve tektonik evrimi”, Türkiye Jeoloji Kurumu Bülteni, Cilt 29, ss. 157-171.

Ketin, I, 1966, “Anadolu'nun Tektonik Birlikleri (Tectonic Units of Anatolian Asia Minor)”, Maden Tetkik ve Arama Enstitüsü Dergisi, Cilt 66, ss. 20-34.

Koç, A., Kaymakçı, N., Van Hinsbergen, D.J., Kuiper, K.F., Vissers, R.L., 2012, “Tectono-Sedimentary evolution and geochronology of the Middle Miocene Altınapa Basin, and implications for the Late Cenozoic uplift history of the Taurides, southern Turkey", Tectonophysics, Vol. 532, pp. 134155.

Korkmaz-Gençoğlu, G., Asan, K., Kurt, H., Morgan, G., 2017. “40Ar/39Ar geochronology, elemental and $\mathrm{Sr}-\mathrm{Nd}-\mathrm{Pb}$ isotope geochemistry of the Neogene bimodal volcanism in the Yükselen area, NW Konya (Central Anatolia, Turkey)", Journal of African Earth Sciences, Vol. 129, pp. 427-444.

Kurt, H., 1994, Petrography and Geochemistry of Kadınhanı (Konya) Area, Central Turkey, PhD Thesis, Glasgow University, UK.

Kurt, H., 1996, "Geochemical characteristics of the metaigneous rocks near Kadınhanı (Konya), Turkey", Geosound, Vol. 28, pp. 1-22.

Kurt, H., 1997, "Petrochemistry of metabasites in the metapelitic rocks of the North of Yükselen (Kadınhanı), Konya". Selçuk Üniversitesi Dergisi, Cilt 20, ss. 329-339.

Niehoff, W., 1961, “1/100 000 ölçekli Akşehir 90/2 paftası, Ilgın 91/1, 91/3 ve 91/4 paftaları üzerine yapılan revizyon çalışmaları", Maden Tetkik ve Arama Enstitüsü, Derleme Rapor, Rapor No. 3387.

Okay, A.I., 1986, "High Pressure/Low Temperature Metamorphic Rocks of Turkey: in Blueschists and Eclogites", The Geological Society of America, Memories, Vol. 164, pp. 338-348.

Özcan, A., Göncüoğlu, M.C., Turan, N., Uysal, S., Sentürk, K., Iş1k, A., 1988, “Late Paleozoic evolution of the Kütahya-Bolkardagi beIt", METU Journal of Pure and Applied Science, Vol. 21, No. 1/3, pp. 211220.

Özdamar, Ş., Billor, M.Z., Sunal, G., Esenli, F., Roden, M.F., 2013, “First U-Pb SHRIMP Zircon and 40Ar/39Ar Ages of Metarhyolites From the Afyon-Bolkardag Zone, SW Turkey: Implications For the Rifting and Closure of the Neo-Tethys", Gondwana Research, Vol. 24, No. 1, pp. 377-391.

Özgül, N., 1976, “Toroslar'ın bazı temel jeolojik özellikleri”, Türkiye Jeoloji Kurumu Bülteni, Cilt 19, ss. 6578.

Özgül, L., Göncüoğlu M.C., “Koçkaya Metamorfik Kompleksi'nin Metamorfik Evrimi: Batı Orta Anadolu'da YB/DS Metamorfizmalı Tektonik Bir Birim”, 52. Türkiye Jeoloji Kurultayı Bildirileri, Ankara, 279-286, 1999.

Ramsay, J.G., 1967, Folding and Fracturing of Rocks, McGraw-Hill, New York, U.S.A.

Robertson, A.H.F., Ustaömer, T., 2009, "Formation of the Late Palaeozoic Konya Complex and Comparable Units in Southern Turkey by Subduction-Accretion Processes: Implications For the Tectonic Development of Tethys in the Eastern Mediterranean Region", Tectonophysics, Vol. 473, No. 1-2, pp. 113-148. 
Robertson, A.H.F., Parlak, O., “Ustaömer, T., 2009, “Melange Genesis and Ophiolite Emplacement Related to Subduction of the Northern Margin of the Tauride-Anatolide Continent, Central and Western Turkey", Geological Society, London, Special Publications, Vol.311, No. 1, pp. 9-66.

Robertson, A.H.F., Parlak, O., Ustaömer, T., 2013, “Late Palaeozoic-Early Cenozoic Tectonic Development of Southern Turkey and the Easternmost Mediterranean Region: Evidence From the InterRelations of Continental and Oceanic Units", Geological Society, London, Special Publications, Vol. 372, No. 1, pp. 9-48. 